\title{
Dysfunction in nitric oxide synthesis in streptozotocin treated rat aorta and role of methylglyoxal.
}

\author{
Yousif A Shamsaldeen1, 2*, Mahdi H Alsugoor1,3, Lisa A Lione ${ }^{1}$ and Christopher D Benham ${ }^{1}$ \\ 1 Pharmacology Group, School of Life and Medical Sciences, University of Hertfordshire, College Lane, \\ Hatfield, Hertfordshire, AL10 9AB \\ 2 Present author address: Department of Physiology and Pharmacology, Biomedical Sciences Building, \\ University of Bristol, Bristol, BS8 1TD \\ 3 Present author address: College of Al-Qunfudah Health Sciences, Umm-Alqura University, Kingdom of \\ Saudi Arabia \\ * Correspondence: yousefshamsaldeen@hotmail.com
}

\begin{abstract}
Diabetic vascular dysfunction is a major complication of diabetes. Methylglyoxal (MGO) is a dicarbonyl metabolite elevated in diabetic plasma that reacts with interstitial molecules to form advanced glycation end products (AGE). We investigated whether MGO affects the release of nitric oxide (NO) from rat aortic smooth muscle cells (ASMCs), and if L-arginine can prevent these effects of MGO. MGO was significantly elevated in serum from streptozotocin (STZ)-treated rats $(121 \pm 11.2$ $\mu \mathrm{M})$ compared with vehicle control rats $(27.5 \pm 9.2 \mu \mathrm{M})$. The pathological concentration of MGO (100 $\mu \mathrm{M})$ was then applied to investigate its effect on inducible nitric oxide synthase (iNOS) expression and NO release on interferon-gamma (IFN- $\gamma)(100 \mathrm{IU} / \mathrm{ml})$ and lipopolysaccharide (LPS) $(100 \mu \mathrm{g} / \mathrm{ml})-$ stimulated control ASMCs. MGO $(100 \mu \mathrm{M})$ inhibited IFN- $\gamma$ and LPS-stimulated iNOS expression through inhibiting Akt phosphorylation and inhibition of iNOS expression was prevented by Larginine $(100 \mu \mathrm{M})$ co-treatment. These findings show for the first time that MGO inhibits IFN- $\gamma$ and LPS-stimulated iNOS expression in ASMCs, in addition to inhibiting IFN- $\gamma$ and LPS-induced Akt phosphorylation. The actions of MGO might contribute to the vascular dysfunction induced by MGO in diabetes.
\end{abstract}

Keywords: Methylglyoxal; Diabetes mellitus; Nitric oxide; iNOS; vascular dysfunction; Larginine

\section{Introduction}

Vascular dysfunction is a major complication of diabetes where vasodilation is compromised rendering the diabetics prone to hypertension and microvascular dysfunction-induced organ damage such as nephropathy and myocardial infarction (American Diabetes Association, 2012). As a consequence of chronic hyperglycemia where blood glucose concentration exceeds $7 \mathrm{mmol} / \mathrm{l}$ (125 $\mathrm{mg} / \mathrm{dl}$ ) (Sheader et al., 2001), approximately $0.5 \%$ of glycolysis generates reactive carbonyl species such as methylglyoxal (MGO) that is a precursor for reactive oxygen species (ROS). MGO reacts with various cellular and interstitial molecules such as proteins and phospholipids to form stable adducts and advanced glycation end products (AGE) (Uchida, 2000). Upon forming AGE, MGO is trapped intracellularly and subsequently increases the oxidative stress (OS). The resulting disruption of cell membrane integrity allows MGO leakage to the serum from where it can be measured for the assessment of disease progression and severity (Kalapos, 2013; Sheader et al., 2001).

Nitric oxide (NO) is a potent vasodilator that is generated by NO synthase (NOS), which oxidizes the substrate L-arginine into L-citrulline (Lin et al., 2003). NOS exists in three major isoforms, endothelial NOS (eNOS), inducible NOS (iNOS) and neuronal NOS (nNOS). A considerable body of work has suggested that endothelial dysfunction in diabetes and other chronic vascular pathologies includes reduced NO production through eNOS dysfunction in endothelial cells (Vanhoutte et al., 2016). Much less studied is the calcium-independent NOS isoform, iNOS that is expressed predominantly in vascular smooth muscle cells, mediating vasodilation and contributes to 
Accepted version of: Shamsaldeen, Y., Alsugoor, M., Lione, L., \& Benham, C. (2019). Dysfunction in nitric oxide synthesis in streptozotocin treated rat aorta and role of methylglyoxal. European Journal of Pharmacology, 842, 321-328. [EJP-48005R3]. https://doi.org/10.1016/j.ejphar.2018.10.056

inflammatory responses (Kleinert et al., 2004). Vascular smooth muscle cells' iNOS-derived NO is an important mechanism of vascular relaxation induced by drugs such as the oestrogen receptor modulator raloxifene (Wong et al., 2017). The contribution of this source of NO in disease states such as diabetes is less clear with some reports showing an increase in iNOS expression and NO release from vascular smooth muscle cells (Di Pietro et al., 2013; Nagareddy et al., 2005). Lipopolysaccharide (LPS), the bacterial endotoxin, evokes strong inflammatory responses and has been used as a tool for induction of iNOS. LPS-induced iNOS releases NO that reduces the noradrenaline (NA)-induced vasoconstriction, by activating calcium activated potassium channels (Kca channels) (Hall et al., 1996). Moreover, other studies have shown iNOS expression, following LPS infusion in vivo, reduces NAinduced vasoconstriction through activation of the cGMP pathway (Gray et al., 1991; Wu et al., 1994), and tension changes are dependent on extracellular L-arginine (Schott et al., 1993).

In this study, we show in streptozotocin (STZ) diabetic rats, that NA-induced vasoconstriction increases alongside increases in serum levels of MGO. We then investigate the hypothesis that this enhanced exaggerated vasoconstriction might be due to a reduction in NO-mediated relaxation resulting from changes in iNOS expression. In aortic smooth muscles cells (ASMCs) cultured from STZ-treated rats, iNOS expression and iNOS-induced NO release were compared to ASMCs from control rats. We next investigated the direct effects of MGO on iNOS expression and iNOS-induced NO from control ASMCs to see if MGO could inhibit iNOS function, and whether the NOS substrate and MGO scavenger, L-arginine is able to reverse these MGO effects.

\section{Materials and Methods}

\subsection{Reagents}

Bicinchoninic acid (BCA) assay reagents, protein assay reagent A (11881345) and protein assay reagent B (10475944), and cell culturing reagents, Dulbecco's Modified Eagle Medium (DMEM) (10135082), newborn bovine calf serum (10014173), antibiotic/antimycotic solution (100x) (10101043), trypsin 2.5\% (10217723), Hanks' Balanced Salt Solution (HBSS) (10X) (10227632) were purchased from Fisher-Scientific (Loughborough, UK). Membrane filter Immobilon-P transfer membranes $0.45 \mu \mathrm{m}$ pore size (IPVH00010) were all purchased from Fisher-Scientific (Loughborough, UK). Streptozotocin (S0130), L- noradrenaline (A7257), L-arginine (A5006), methylglyoxal (M0252), lipopolysaccharides from Escherichia coli 0111:B4 (100MG) (L2630), luminol (A8511), p-coumaric acid (C9008), goat antirabbit IgG (whole molecule)-peroxidase antibody (a6154) produced in goat and mouse monoclonal anti- $\beta$-actin-peroxidase antibody (A3854) were all purchased from Sigma Aldrich (Gillingham, UK). Interferon- $\gamma$, rat, recombinant, E. coli (407321) was purchased from Merck chemicals (Nottingham, UK). Biotinylated protein ladder detection pack (7727S) was purchased from New England biolabs (Hitchin, UK). Rabbit anti-iNOS antibody $(200 \mu \mathrm{l})$ (ab3523) was purchased from Abcam (Cambridge, UK). Anti phospho-Akt (9271) and anti MAPK p38 (9211) were purchased from Cell Signalling UK.

\subsection{STZ-diabetes modelling}

All rats were kept under standard housing conditions with freely available food and water at controlled temperature $20 \pm 2^{\circ}$, humidity at $55 \pm 10 \%$ and $12 \mathrm{~h}$ day-night cycle, all studies were approved by the Institutional Animal Welfare and Ethics review committee and conducted in accordance with guidelines established by the Animals (Scientific Procedures) Act 1986 and European directive 2010/63/EU carried out under project license PPL70/7732. For STZ-diabetes induction, male Wistar rats (350-450 g) (Charles River, UK) were housed in pairs and given a single injection of 65 $\mathrm{mg} / \mathrm{kg}$ streptozotocin (STZ; dissolved in $20 \mathrm{mM}$ citrate buffer $\mathrm{pH} 4.5$ ) intraperitoneally (i.p., DV 10 $\mathrm{ml} / \mathrm{kg}$ ) (De la Garza-Rodea et al., 2010). For $48 \mathrm{~h}$ following STZ or control injection (20 mM citrate buffer) an additional choice of $2 \%$ sucrose solution was provided, to avoid the initial hypoglycemia that is seen following STZ administration. For all control and STZ-injected rats, food was also changed from $14 \%$ protein (LabDiet 5LF2, EURodent Diet 14\%) into protein rich diet 22\% protein 
Accepted version of: Shamsaldeen, Y., Alsugoor, M., Lione, L., \& Benham, C. (2019). Dysfunction in nitric oxide synthesis in streptozotocin treated rat aorta and role of methylglyoxal. European Journal of Pharmacology, 842, 321-328. [EJP-48005R3]. https://doi.org/10.1016/j.ejphar.2018.10.056

(LabDiet 5LF5, EURodent Diet 14\%) after injection to compensate possible diabetes-induced protein loss.

Body weight was monitored every day for a minimum of 2 weeks post injection, and diabetes was confirmed by testing a drop of tail vein blood (Accu-check blood glucose monitor); rats showing an elevated blood glucose $>16 \mathrm{mmol} / \mathrm{l}$ were considered diabetic. Blood glucose levels were measured at three-time periods; (i) Prior to STZ or vehicle injection, (ii) 2-7 days post injection, and (iii) Prior to euthanizing (week 1 to week 5).

\subsection{Serum MGO measurement}

Serum samples were analyzed through sandwich ELISA according to the manufacturer's instructions (Cell Biolabs, STA-811). Briefly, a sterile 96 well plate was coated with $100 \mu \mathrm{l}$ of $50 \mathrm{ng} / \mathrm{ml}$ MGO conjugate which was prepared by the supplier through reacting bovine serum albumin (BSA) with MGO, followed by extensive dialysis and column purification. Serum samples (50 $\mu \mathrm{l})$ were incubated at $25^{\circ}$ for $10 \mathrm{~min}$ prior to the addition of primary monoclonal mouse anti-MGO antibody $(50 \mu \mathrm{l})$; samples were incubated at room temperature on an orbital shaker for 1 hour. All samples were washed with washing buffer before the addition of $100 \mu \mathrm{l}$ secondary horseradish labelled goat antimouse antibody for 1 hour on an orbital shaker. Wells were washed three times and then incubated with 3,3',5,5'-Tetramethylbenzidine (TMB) substrate solution (100 $\mu \mathrm{l})$ for $5 \mathrm{~min}$; the reaction was stopped using $100 \mu \mathrm{l}$ sulphuric acid stop solution and absorbance measured at $450 \mathrm{~nm}$.

\subsection{Aortic rings contraction studies:}

To examine the extent of vasoconstriction in STZ-diabetic rats and vehicle control rats, as previously mentioned (Shamsaldeen et al., 2018), rats were euthanized through schedule 1 procedures that includes $\mathrm{CO}_{2}$ asphyxiation and spinal dislocation. Thereafter, thoracic aorta was freshly dissected and plunged into oxygenated Krebs solution and cut into 1-2 mm rings. Then, the aortic rings were hung in a Bennett isolated tissue organ bath filled with Krebs solution $\mathrm{pH} 7.4$ at $37^{\circ} \mathrm{C} \pm 1^{\circ} \mathrm{C}$ and gassed with $95 \% \mathrm{O} 2 / 5 \% \mathrm{CO} 2$. Aortic rings were equilibrated for $60 \mathrm{~min}$ before conducting any experiment. Aortic ring's response was measured through FT-100 force transducer and iWORKS amplifier that generates electrical signals recorded through Labscribe software from iWORKS (version 1.817). Aortic rings were treated with freshly prepared EC $80(300 \mathrm{nM})$ concentration of NA, and tension was measured. The increase in tension was measured above baseline value $(1 \mathrm{~g})$ before adding the vasoconstrictor.

\subsection{Primary aortic smooth muscle cells studies}

Primary rats' ASMCs were extracted through explants. Briefly, thoracic aorta was isolated from vehicle and STZ-treated rats and plunged into complete Dulbecco's Modified Eagle Medium (DMEM) with L-glutamine $1000 \mathrm{mg} / \mathrm{l}$, D-glucose, sodium pyruvate, $25 \mathrm{mM}$ HEPES supplemented with $15 \%$ new born calf serum and streptomycin $(100 \mu \mathrm{g})$ penicillin (100 units). The aorta was mechanically stripped from the adventitia and cut into small rings, and endothelium removed using autoclaved forceps. The flask was added with $3 \mathrm{ml}$ complete media and placed vertically in the incubator to allow the adherence of the explants for $90 \mathrm{~min}$. The flask is then placed horizontally so the explants are supplemented with media. Cell growth was checked daily and half of the media was changed after 4 days (Kenagy et al., 1997). The cells were grown to reach approximately 100\% confluence before being trypsinized and transferred into T-75 flasks where they were grown to reach approximately $100 \%$ confluence. Once confluent, the cells were plated into 12 well plates in approximately 300000 cell/ml/well. The next day, cells were refreshed with new complete media and after $48 \mathrm{~h}$ from plating, the ASMCs were confluent and used for experiments. Western blots were analyzed through ImageJ 1.46r, and each protein band was analyzed through densitometric analysis by being normalized to its correspondent $\beta$-actin. Afterward, the densitometric results were normalized to the densitometric result of the IFN + LPS positive control as $\%$. 
Accepted version of: Shamsaldeen, Y., Alsugoor, M., Lione, L., \& Benham, C. (2019). Dysfunction in nitric oxide synthesis in streptozotocin treated rat aorta and role of methylglyoxal. European Journal of Pharmacology, 842, 321-328. [EJP-48005R3]. https://doi.org/10.1016/j.ejphar.2018.10.056

\subsection{Total nitrite $\left(\mathrm{NO}_{2}\right)$ measurement}

Confluent ASMCs were washed three times with HBSS, before adding complete media with IFN$\gamma(100 \mathrm{IU} / \mathrm{ml})$ and LPS $(100 \mu \mathrm{g} / \mathrm{ml})$ together with different concentrations of MGO representing the physiological and pathological concentration (10 and $100 \mu \mathrm{M}$, respectively) as well as without MGO (positive control) in addition to untreated cells (negative control). The cells were then incubated at $37^{\circ}$ $\mathrm{CO}_{2} 5 \%$ for $24 \mathrm{~h}$. Nitric oxide (NO) was estimated indirectly through total nitrite $\left(\mathrm{NO}_{2}\right)$ measurement. The reaction based on oxidizing all produced $\mathrm{NO}$ into $\mathrm{NO}_{2}$ from $100 \mu \mathrm{l}$ of the well media which was then added with $100 \mu \mathrm{l}$ Griess mixed reagents A and B (1:1 Griess reagents ratio), Sulfanilamide and N-1-naphthylethylenediamine, respectively. The reaction generates pink azo dye proportional to the total $\mathrm{NO}_{2}$ concentration. The samples were then read at $540 \mathrm{~nm}$ with an automated spectrophotometer (Coneski and Schoenfisch, 2012). Afterward, the total $\mathrm{NO}_{2}$ release was normalized to the total $\mathrm{NO}_{2}$ released from ASMCs treated with LPS and IFN- $\gamma$ only (positive control), with the $\mathrm{NO}_{2}$ released in the positive control normalized as $100 \%$.

\subsection{Statistical analysis}

Data were analyzed through GraphPad Prism (version 5). Data are expressed as mean \pm S.E.M. and compared through one-way ANOVA post hoc Tukey's test, two-way ANOVA post hoc Bonferroni's test or unpaired Student t-test. The P-value was considered significant when less than 0.05 .

\section{Results}

\subsection{Blood glucose was significantly elevated in STZ-diabetic rats}

Blood glucose was measured to confirm that the STZ-injected rats develop hyperglycemia. 95\% of STZ-injected rats developed hyperglycemia characterized by blood glucose concentration $>16 \mathrm{mmol} / 1$ from week 1 as shown in Fig. 2. Hyperglycemia was sustained over the 5 weeks period of study.

\subsection{Methylglyoxal was significantly increased in serum from STZ-treated rats associated with increased NA-induced vasoconstriction:}

ELISA assay of MGO showed a significant increase in serum MGO in STZ-treated rats; greater than 5-fold higher than vehicle control rat serum $(18.7 \pm 3.7 \mu \mathrm{M}$ ) from week 1 to week 5 (from $97.0 \pm$ $26.4 \mu \mathrm{M}$ to $201.2 \pm 44.4 \mu \mathrm{M}$ ) as shown in Fig. 3A. Diabetic vascular tissue is well known to show increased contractility and we next sought to establish the time course of this pathology in our model. Aortic rings were exposed to the EC80 concentration of $300 \mathrm{nM}$ NA until tension plateaued. Significant increase in vascular contractility was observed in all STZ-diabetic rats' aortic rings (Fig. 3B). Moreover, it should be noted that the EC80 was similar in aortic rings from both STZ and vehicle control rats.

\section{3. iNOS expression was significantly suppressed in STZ-diabetic primary ASMCs}

As previously reported, LPS induces iNOS expression and therefore, NO release that causes vasodilation and hypo-reactivity to vasoconstrictors such as phenylephrine (Hall et al., 1996). So, we next investigated whether iNOS expression is also impaired in diabetes and what might contribute to such an effect. Confluent primary ASMCs were treated with a standard inflammatory cocktail, interferon-gamma (IFN- $\gamma)(100 \mathrm{IU} / \mathrm{ml})$ and lipopolysaccharide (LPS) $(100 \mu \mathrm{g} / \mathrm{ml})$ to induce iNOS (Uemura et al., 2002). The Griess assay and SDS-PAGE Western blotting were performed to assess total nitrite $\left(\mathrm{NO}_{2}\right)$ production and iNOS protein levels respectively. 
Accepted version of: Shamsaldeen, Y., Alsugoor, M., Lione, L., \& Benham, C. (2019). Dysfunction in nitric oxide synthesis in streptozotocin treated rat aorta and role of methylglyoxal. European Journal of Pharmacology, 842, 321-328. [EJP-48005R3]. https://doi.org/10.1016/j.ejphar.2018.10.056

Total $\mathrm{NO}_{2}$ release and iNOS expression from primary ASMCs isolated from naïve and STZ-treated rats were compared. ASMCs isolated from STZ-treated rats incubated with IFN- $\gamma$ and LPS (positive STZ) for $24 \mathrm{~h}$ showed significantly less increase in iNOS expression compared to control ASMCs (Fig. 4C). Total $\mathrm{NO}_{2}$ release was also significantly reduced in STZ-diabetic ASMCs (Fig. 4D).

\subsection{MGO significantly suppressed iNOS expression and $\mathrm{NO}_{2}$ release in control ASMCs}

Since ASMCs from STZ-treated rats (2-3 week) with chronically elevated MGO levels showed significant reduction in total $\mathrm{NO}_{2}$ release and iNOS expression following IFN- $\gamma$ and LPS induction (Fig. 4), we next looked at the effect of acute MGO treatment on total $\mathrm{NO}_{2}$ release and iNOS expression in naïve rat primary ASMCs. ASMCs were treated with IFN- $\gamma$ and LPS to stimulate iNOS expression and $\mathrm{NO}_{2}$ production in the presence of $\mathrm{MGO}$ at physiological and pathological concentrations, $10 \mu \mathrm{M}$ and $100 \mu \mathrm{M}$, respectively. Moreover, since a previous study showed MGO (100 $\mu \mathrm{M}$ ) inhibitory effect on eNOS activation when aortic rings were incubated with MGO for $2 \mathrm{~h}$ (Dhar et al., 2010), therefore, two different incubation periods were studied; $2 \mathrm{~h}$ and $24 \mathrm{~h}$. Accordingly, when ASMCs were incubated with IFN- $\gamma$, LPS and $100 \mu \mathrm{M}$ MGO for $24 \mathrm{~h}$ a significant reduction in iNOS expression and total $\mathrm{NO}_{2}$ release was seen, but not with $10 \mu \mathrm{M}$ MGO. Incubating ASMCs with IFN- $\gamma$ and LPS for $24 \mathrm{~h}$ and with $100 \mu \mathrm{M}$ MGO for $2 \mathrm{~h}$ causes non-significant reduction to iNOS expression and total $\mathrm{NO}_{2}$ release (Fig. 5).

These results suggest that the increased NA evoked tension seen after STZ treatment might be due to inhibition of iNOS expression. We thus tested this in intact aorta with endothelium removed to mirror the ASMCs cultures. Endothelium denuded rings (produced by gentle rubbing with a cotton wool bud)were treated with L-NAME for $30 \mathrm{~min}$ to inhibit ASMCs NOS before the $300 \mathrm{nM}$ NA addition. In this experiment denuded rings treated with L-NAME showed significantly greater NAinduced tension $0.47 \pm 0.05 \mathrm{~g}$ compared to untreated controls $0.30 \pm 0.02 \mathrm{~g}, \mathrm{P}<0.01$, consistent with the idea that there is resting NOS mediated NO release in ASMC in intact aorta rings.

\subsection{Methylglyoxal significantly inhibited Akt phosphorylation but not MAPK p-38 in control ASMCs}

Previous studies have shown that Akt phosphorylation is essential for IFN- $\gamma /$ LPS-induced iNOS expression in vascular smooth muscle cells (VSMCs) (Hattori et al., 2003). Moreover, mitogen activated protein kinase (MAPK) p38 phosphorylation was shown to be involved in insulin-induced iNOS expression in VSMCs (Begum and Ragolia, 2000). We thus next looked at levels of phospho-Akt (Ser473) and phospho-p38 (Thr180/Tyr182) in our ASMCs cultures to investigate the mechanism through which iNOS was inhibited.

ASMCs incubated with IFN- $\gamma$ and LPS for $24 \mathrm{~h}$ showed a significant increase in phospho-Akt and this increase was blocked by incubation with IFN- $\gamma$, LPS and MGO $100 \mu \mathrm{M}$ for $24 \mathrm{~h}$ (Fig. 6).

However, when ASMCs were incubated with IFN- $\gamma$, LPS and MGO $100 \mu \mathrm{M}$ for $24 \mathrm{~h}$ it did not show significant reduction in phosphorylated-p38, nor did IFN- $\gamma$ and LPS treatment alone induce an increase in phosphorylated-p38 (Fig. 7).

\subsection{L-arginine treatment reversed MGO-induced iNOS inhibition}

L-arginine has been shown to reverse the effects of MGO on NO production in some systems and this has been suggested to be due to an MGO scavenging effect or to competition at the NOS substrate site (Dhar et al., 2010). So, it was of interest to investigate the effect of L-Arginine on the MGOinhibitory effect on iNOS expression. L-Arginine added to ASMCs in addition to IFN- $\gamma$, LPS and MGO reversed the inhibitory effect of MGO on IFN- $\gamma$ and LPS-induced iNOS expression. L-Arginine did not significantly change the IFN- $\gamma$ and LPS-induced increase in iNOS expression by itself nor did 
Accepted version of: Shamsaldeen, Y., Alsugoor, M., Lione, L., \& Benham, C. (2019). Dysfunction in nitric oxide synthesis in streptozotocin treated rat aorta and role of methylglyoxal. European Journal of Pharmacology, 842, 321-328. [EJP-48005R3]. https://doi.org/10.1016/j.ejphar.2018.10.056

it change levels of basal iNOS expression Fig. 8C. Similar effects of L-Arginine were seen on total $\mathrm{NO}_{2}$ release. L-Arginine blocked the inhibition of total $\mathrm{NO}_{2}$ release by MGO without affecting IFN- $\gamma$ and LPS-induced total $\mathrm{NO}_{2}$ release or basal levels of total $\mathrm{NO}_{2}$ release (Fig. 8D). Taken together this Data are consistent with the hypothesis that L-Arginine is acting as a scavenger of MGO preventing the inhibition of iNOS induction.

\section{Discussion}

Blood glucose concentration was used as a marker for diabetes as rats were considered diabetic when their blood glucose readings exceed $16 \mathrm{mmol} / \mathrm{l}$. STZ was shown to induce hyperglycemia (4fold blood glucose increase) in $95 \%$ of the STZ-injected rats. This study was conducted between week 1-5 post-STZ injection which showed significant increase in blood glucose as shown in Fig. 2, these findings were similar to what was reported in a previous study (Bagri et al., 2009). This is essentially a model of type 1 diabetes.

MGO was significantly increased in blood from STZ-treated rats by approximately 5 -fold to about $100 \mu \mathrm{M}$ (Fig. 3A). This is similar to the MGO concentration (100 $\mu \mathrm{M})$ applied by Dhar et al. (2010) to aortic rings to examine MGO-induced endothelial dysfunction. The elevation in serum MGO was accompanied by a 4 -fold increase in blood glucose concentration, consistent with the idea that glycolysis is the main endogenous pathway for MGO generation (Sheader et al., 2001). MGO is generated during glycolysis by triose-phosphate enzymatic metabolism which was found to be increased in hyperglycemia (Kalapos, 2013; Thornalley et al., 2001). In addition to glycolysis, lipid catabolism (lipolysis) and protein catabolism (proteolysis) are also major endogenous MGO sources (Kalapos, 2013; Shamsaldeen et al., 2016). Lipolysis involves triose-phosphate generation through $\alpha$ glycerol-phosphate dehydrogenase-metabolized glycerol (Kalapos, 2013). Additionally, lipolysis is increased in diabetes and suppression of lipolysis improves insulin sensitivity and glucose utilization (Arner and Langin, 2014; Lim et al., 2011).

In STZ-treated rats' serum MGO levels and NA-induced vascoconstriction both increased significantly from week 1 . From week 1-5 MGO levels varied around a level of $120 \mu \mathrm{M}$ while NAinduced vasoconstriction continued to slowly increase to approximately double control levels. This difference in timecourse might be due to complex pharmacodynamics resulting from MGO exposure, or it may mean that other factors also affect contractility. Mean MGO levels were variable and were not significantly above control at 4 weeks. Taken together with the other weekly MGO levels we attribute this lack of significance to the reduced power of $\mathrm{N}=4 \mathrm{MGO}$ samples at this timepoint.

Aortic rings from STZ-diabetic rats showed significantly increased NA-induced vasoconstriction when compared with vehicle control aortic rings (Fig. 3B) without any change in EC80. This suggests that affinity of NA binding was not affected by MGO and that the MGO effect is due to downstream signaling changes increasing response efficacy. This is consistent with a reduction in NO signaling.

Our experiments with isolated ASMCs showed good association between, iNOS levels and total $\mathrm{NO}_{2}$ production, suggesting that iNOS is the major source of $\mathrm{NO}$ in these experiments. Recent work by Wong et al. suggests that iNOS generated NO can induce significant vasodilation when stimulated by drugs such as raloxifene (Wong et al., 2017). In addition, iNOS-derived NO plays a preventive role against increased vasoconstriction responses in the inflammatory conditions associated with arteriosclerosis (Fukumoto et al., 1997). We have not excluded the possibility that nNOS contributes as there is some evidence that nNOS is expressed in some ASMCs although this varies in different strains (Boulanger et al., 1998).

The significant reduction in iNOS expression from STZ ASMCs stimulated with IFN- $\gamma$ and LPS (Fig. 4) differs from results of other studies. Diabetic ASMCs when treated with LPS only, rather than 
Accepted version of: Shamsaldeen, Y., Alsugoor, M., Lione, L., \& Benham, C. (2019). Dysfunction in nitric oxide synthesis in streptozotocin treated rat aorta and role of methylglyoxal. European Journal of Pharmacology, 842, 321-328. [EJP-48005R3]. https://doi.org/10.1016/j.ejphar.2018.10.056

IFN- $\gamma$ and LPS, showed iNOS upregulation (Di Pietro et al., 2013; Nagareddy et al., 2005). The differences may be due to inflammatory stimulus or perhaps more likely diabetic model and or time of study, as Di Pietro et al. used a partial pancreatectomy model and Nagareddy et al. looked mostly at a 12-week time point. Overall levels of iNOS activity may be due to a combination of stimulatory effects of diabetes mediated inflammatory stimuli and inhibition due to factors such as MGO levels (next section).

To the best of our knowledge this is the first study to examine the effect of MGO on iNOS expression on primary ASMCs treated with IFN- $\gamma$ and LPS. IFN- $\gamma$ and LPS are known iNOSinducers, and they are involved in immunogenic inflammatory response since IFN- $\gamma$ is an inflammatory mediator, while LPS is a bacterial cell wall component (Kleinert et al., 2004). MGO was applied in both physiological $(10 \mu \mathrm{M})$ and pathological concentrations seen in our diabetes model $(100 \mu \mathrm{M})$ on primary ASMCs treated with IFN- $\gamma$ and LPS. Treatment of ASMCs for $24 \mathrm{~h}$ (and not $2 \mathrm{~h}$ ) with diabetic levels of MGO $(100 \mu \mathrm{M})$ suppressed iNOS expression which was accompanied with greatly reduced NO release (Fig. 5). Thus, in addition to MGO being an eNOS inhibitor (Dhar et al., 2010), MGO suppresses iNOS expression (Fig. 5).

Akt and p38 phosphorylation were investigated as previous reports have showed the essential role of these two protein kinases in regulating iNOS expression (Begum and Ragolia, 2000; Hattori et al., 2003). As shown in Fig. 6, Akt phosphorylation was significantly reduced in ASMCs incubated with IFN- $\gamma(100 \mathrm{IU} / \mathrm{ml})$, LPS $(100 \mu \mathrm{g} / \mathrm{ml})$ and MGO $(100 \mu \mathrm{M})$ over $24 \mathrm{~h}$. A recent study has shown MGO $(500 \mu \mathrm{M})$-induced apoptosis of endothelial cells through inhibiting Akt phosphorylation as well as suppressing other survival factors such as Bcl-2 protein (Chu et al., 2016). Another study has concluded that MGO $(500 \mu \mathrm{M})$ prevented the insulin-dependent activation of the IRS1/protein kinase Akt/eNOS pathway, thus reducing NO production in mouse aortic endothelial cells (Nigro et al., 2014). P-Akt phosphorylates $I \kappa B$, tagging it for ubiquitination and degradation. Once I $\mathrm{B}$ is degraded, nuclear factor $\kappa \mathrm{B}(\mathrm{NF}-\kappa \mathrm{B})$ becomes active and translocates into the nucleus to induce iNOS expression (Hattori et al., 2003). A recent study conducted where iNOS-induced vasodilation was significantly suppressed by NF- $\kappa B$ inhibitor pyrrolidine dithiocarbamate $(3 \mu \mathrm{M})$ (Wong et al., 2017) is consistent with this mechanism. Lower concentrations of MGO may have different effects. Chang et

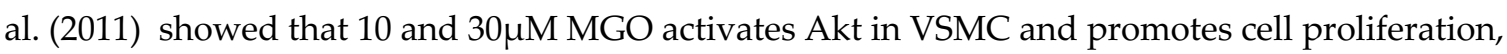
while $10 \mu \mathrm{M}$ MGO did not show any significant effect in our model on iNOS levels, so we did not directly test its effect on Akt.

In contrast to Akt, p38 phosphorylation was not significantly affected by MGO treatment (Fig. 7). However, as p-38 MAPKs are rapidly activated within $0.5-3 \mathrm{~h}$, a full time course study would be needed to exclude any effect of MGO on p-38 MAPKs in regulating iNOS expression (Chan and Riches, 2001). These authors also showed that both ERK and JNK MAPKs are also involved in modulating the IFN- $\gamma$ and LPS-stimulated iNOS (Chan and Riches, 2001). Also, human umbilical vein endothelial cells showed MGO-induced concentration-dependent activation of JNK and p38 MAP kinase (Yamawaki et al., 2008) Therefore, it would be interesting to investigate the effect of MGO on these two MAPKs in addition to Akt and p-38.

Taken together with Fig. 6 the data shows that MGO prevents IFN- $\gamma$ + LPS-induced Akt phosphorylation and such an effect may contribute to increased vasospastic responses shown in Fig. 3B since iNOS-derived NO plays a preventive role against increased vasospastic responses (Fukumoto et al., 1997). Moreover, since Akt plays a major role in glucose metabolism in addition to being a cell survival factor (Franke et al., 1997), MGO elevation in diabetes might exacerbate the effects of hyperglycaemia (Dhar et al., 2011; Nicolay et al., 2006; Ramasamy et al., 2005). 
Accepted version of: Shamsaldeen, Y., Alsugoor, M., Lione, L., \& Benham, C. (2019). Dysfunction in nitric oxide synthesis in streptozotocin treated rat aorta and role of methylglyoxal. European Journal of Pharmacology, 842, 321-328. [EJP-48005R3]. https://doi.org/10.1016/j.ejphar.2018.10.056

A previous study revealed that $300 \mu \mathrm{M}$ L-arginine serves as an MGO scavenger (Dhar et al., 2012). Therefore, in this study L-arginine was applied to MGO-treated ASMC cultures which showed that L-arginine restores iNOS expression by LPS and IFN- $\gamma$ in the presence of MGO (Fig. 8). As Larginine reverses the effect of MGO on iNOS expression, this suggests that adding exogenous Larginine is not merely providing further substrate for iNOS. If this was the case, we might expect to see an increase in total $\mathrm{NO}_{2}$ production with no change in iNOS protein levels. L-arginine by itself is unable to significantly induce iNOS, and when added with LPS and IFN, it did not show significant induction when compared to the positive control of LPS and IFN alone ( $P \geq 0.05)$, further supporting the idea that this is an MGO scavenging effect. In our study, L-arginine was applied as $100 \mu \mathrm{M}$ which is close to the normal plasma concentration $(60-140 \mu \mathrm{M})$ (Schwedhelm et al., 2008). L-arginine supplementation will also help to prevent substrate limitation of NO production which can result in uncoupling of NOS and increased free radical generation. Our findings suggest that L-arginine supplementation may have therapeutic potential for diabetics. Previous studies revealed that Larginine supplementation ( $3 \times 2 \mathrm{~g} /$ day) showed significant improvement in antioxidant levels and NO release (Jabłecka et al., 2012). Moreover, previous studies showed significant improvement in insulin sensitivity in patients with type 2 diabetes when they were given $8.3 \mathrm{~g} /$ day L-arginine. This improvement was accompanied by improved glucose metabolism and antioxidants capacity (Lucotti et al., 2006). A recent meta-analysis found some evidence of a reduction in infection rates (McRae, 2016). These findings suggest further investigation of the clinical benefit of L-arginine as a supplement for diabetic patients is merited (Dhar et al., 2011; Eberhardt et al., 2012; Jia et al., 2006; Van Eupen et al., 2013). Further in vivo experiments on supplementing rats with L-arginine and measuring the vasocontractility response and iNOS-induced NO release in diabetic aortic rings would provide in vivo evidence for the role of L-arginine in reducing the exaggerated vasoconstriction.

\section{Conclusion}

MGO was elevated in serum from STZ-treated rats, iNOS expression and NO release was reduced, and vasoconstriction was exaggerated. These elevated levels of MGO and inhibited iNOS expression may contribute to diabetic complications such as compromised vasodilation and exaggerated vasoconstriction. Incubating control ASMCs with diabetic levels of MGO (100 $\mu \mathrm{M})$ for 24 $\mathrm{h}$ was associated with inhibiting Akt-phosphorylation and iNOS expression which might explain the increased vasoconstriction in aorta rings from STZ-treated rats. L-arginine $(100 \mu \mathrm{M})$ treatment cancelled the MGO-inhibited, IFN-induced iNOS expression. Therefore, further work will be needed to understand if these effects have any potential therapeutic benefit in treating MGO-related diabetic complications such as vascular dysfunction as a previous study revealed the ability of L-arginine to scavenge MGO (Bierhaus et al., 2012; Dhar et al., 2010).

Authors' Contributions: Yousif A Shamsaldeen, Mahdi H Alsugoor, Lisa A Lione and Christopher D Benham conceived and designed the experiments; Yousif A Shamsaldeen and Mahdi H Alsugoor performed the experiments; Yousif A Shamsaldeen analyzed the data; Yousif A Shamsaldeen and Mahdi H Alsugoor contributed reagents/materials/analysis tools; Yousif A Shamsaldeen, Lisa A Lione and Christopher D Benham wrote and proofread the paper.

Acknowledgments: The animal care and housing were provided by the animal unit at the University of Hertfordshire, with exceptional care provided by Mrs. Lena Ioannou and Mr. David Clarke. The work was supported by the ministry of higher education of Kuwait and Umm Al-Qura University in Saudi Arabia.

Conflicts of Interest: The authors declare no conflict of interest. 
Accepted version of: Shamsaldeen, Y., Alsugoor, M., Lione, L., \& Benham, C. (2019). Dysfunction in nitric oxide synthesis in streptozotocin treated rat aorta and role of methylglyoxal. European Journal of Pharmacology, 842, 321-328. [EJP-48005R3]. https://doi.org/10.1016/j.ejphar.2018.10.056

\section{References}

American Diabetes Association, 2012. Diagnosis and Classification of Diabetes Mellitus. Diabetes Care 35, S64-S71.

Arner, P., Langin, D., 2014. Lipolysis in lipid turnover, cancer, cachexia, and obesity-induced insulin resistance. Trends in endocrinology and metabolism 25, 255-262.

Bagri, P., Ali, M., Aeri, V., Bhowmik, M., Sultana, S., 2009. Antidiabetic effect of Punica granatum flowers: Effect on hyperlipidemia, pancreatic cells lipid peroxidation and antioxidant enzymes in experimental diabetes. Food and Chemical Toxicology 47, 50-54.

Begum, N., Ragolia, L., 2000. High glucose and insulin inhibit VSMC MKP-1 expression by blocking iNOS via p38 MAPK activation. American Journal of Physiology - Cell Physiology 278, C81-C91. Bierhaus, A., Flemin, T., Stoyanov, S., Leffler, A., Babes, A., Neacsu, C., Sauer, S.K., Eberhardt, M., Schnölzer, M., Lasischka, F., Neuhuber, W.L., Kichko, T.I., Konrade, I., Elvert, R., Mier, W., Pirags, V., Lukic, I.K., Morcos, M., Dehmer, T., Rabbani, N., Thornalley, P.J., Edelstein, D., Nau, C., Forbes, J., Humpert, P.M., Schwaninger, M., Ziegler, D., Stern, D.M., Cooper, M.E., Haberkorn, U., Brownlee, M., Reeh, P.W., Nawroth, P.P., 2012. Methylglyoxal modification of Nav1.8 facilitates nociceptive neuron firing and causes hyperalgesia in diabetic neuropathy. Nature Medicine, 1-9.

Boulanger, C.M., Heymes, C., Benessiano, J., Geske, R.S., Lévy, B.I., Vanhoutte, P.M., 1998. Neuronal nitric oxide synthase is expressed in rat vascular smooth muscle cells activation by angiotensin ii in hypertension. Circulation research 83, 1271-1278.

Chan, E.D., Riches, D.W., 2001. IFN- $\gamma+$ LPS induction of iNOS is modulated by ERK, JNK/SAPK, and p38 mapk in a mouse macrophage cell line. American Journal of Physiology-Cell Physiology 280, C441C450.

Chang, T., Wang, R., Olson, D.J., Mousseau, D.D., Ross, A.R., Wu, L., 2011. Modification of Akt1 by methylglyoxal promotes the proliferation of vascular smooth muscle cells. The FASEB Journal 25 , 1746-1757.

Chu, P., Han, G., Ahsan, A., Sun, Z., Liu, S., Zhang, Z., Sun, B., Song, Y., Lin, Y., Peng, J., Tang, Z., 2016. Phosphocreatine protects endothelial cells from Methylglyoxal induced oxidative stress and apoptosis via the regulation of PI3K/Akt/eNOS and NF-KB pathway. Vascular Pharmacology. Coneski, P.N., Schoenfisch, M.H., 2012. Nitric oxide release: Part III. Measurement and reporting. Chem. Soc. Rev. 41, 3753-3758.

De la Garza-Rodea, A.S., Knaän-Shanzer, S., den Hartigh, J.D., Verhaegen, A.P.L., van Bekkum, D.W., 2010. Anomer-equilibrated streptozotocin solution for the induction of experimental diabetes in mice (mus musculus). J Am Assoc Lab Anim Sci. 49, 40-44.

Dhar, A., Dhar, I., Desai, K.M., Wu, L., 2010. Methylglyoxal scavengers attenuate endothelial dysfunction induced by methylglyoxal and high concentrations of glucose. British Journal of Pharmacology 161, 1843-1856.

Dhar, A., Dhar, I., Jiang, B., Desai, K.M., Wu, L., 2011. Chronic methylglyoxal infusion by minipump causes pancreatic $\beta$-cell dysfunction and induces type 2 diabetes in Sprague-Dawley rats. Diabetes 60, 899-908.

Dhar, I., Dhar, A., Wu, L., Desai, K., 2012. Arginine Attenuates Methylglyoxal- and High GlucoseInduced Endothelial Dysfunction and Oxidative Stress by an Endothelial Nitric-Oxide SynthaseIndependent Mechanism. The Journal of Pharmacology and Experimental Therapeutics 342, 196204.

Di Pietro, N., Di Tomo, P., Di Silvestre, S., Giardinelli, A., Pipino, C., Morabito, C., Formoso, G., Mariggiò, M.A., Pandolfi, A., 2013. Increased iNOS activity in vascular smooth muscle cells from diabetic rats: Potential role of $\mathrm{Ca} 2+/$ calmodulin-dependent protein kinase II delta 2 (CaMKIIठ 2 ). Atherosclerosis 226, 88-94.

Eberhardt, M.J., Filipovic, M.R., Leffler, A., De la Roche, J., Kistner, K., Fischer, M.J., Flemin, T., Zimmermann, K., Burmazovic, I.I., Nawroth, P.P., Bierhaus, A., Reeh, P., Sauer, S.K., 2012. Methylglyoxal activates nociceptors through transient receptor potential A1 (TRPA1): a possible mechanism of metabolic neuropathies. JBC 287, 28291-28306. 
Accepted version of: Shamsaldeen, Y., Alsugoor, M., Lione, L., \& Benham, C. (2019). Dysfunction in nitric oxide synthesis in streptozotocin treated rat aorta and role of methylglyoxal. European Journal of Pharmacology, 842, 321-328. [EJP-48005R3]. https://doi.org/10.1016/j.ejphar.2018.10.056

Franke, T.F., Kaplan, D.R., Cantley, L.C., 1997. PI3K: downstream aktion blocks apoptosis. Cell 88, 435-437.

Fukumoto, Y., Shimokawa, H., Kozai, T., Kadokami, T., Kuwata, K., Yonemitsu, Y., Kuga, T., Egashira, K., Sueishi, K., Takeshita, A., 1997. Vasculoprotective role of inducible nitric oxide synthase at inflammatory coronary lesions induced by chronic treatment with interleukin-1 $\beta$ in pigs in vivo. Circulation 96, 3104-3111.

Gray, G.A., Schott, C., Julou-Schaeffer, G., Fleming, I., Parratt, J.R., Stoclet, J.C., 1991. The effect of inhibitors of the L-arginine/nitric oxide pathway on endotoxin-induced loss of vascular responsiveness in anaesthetized rats. British Journal of Pharmacology 103, 1218-1224. Hall, S., Turcato, S., Clapp, L., 1996. Abnormal activation of K+channels underlies relaxation to bacterial lipopolysaccharide in rat aorta. Biochemical and Biophysical Research Communications 224, 184-190.

Hattori, Y., Hattori, S., Kasai, K., 2003. Lipopolysaccharide activates Akt in vascular smooth muscle cells resulting in induction of inducible nitric oxide synthase through nuclear factor-kappa $B$ activation. European Journal of Pharmacology 481, 153-158.

Jabłecka, A., Bogdański, P., Balcer, N., Cieślewicz, A., Skołuda, A., Musialik, K., 2012. The effect of oral L-arginine supplementation on fasting glucose, $\mathrm{HbA1c}$, nitric oxide and total antioxidant status in diabetic patients with atherosclerotic peripheral arterial disease of lower extremities. European Review for Medical and Pharmacological Sciences 16, 342-350.

Jia, S., H., O.D.J., Ross, A.R.S., Wu, L., 2006. Structural and functional changes in human insulin induced by methylglyoxal. FASEB 20, E871-E879.

Kalapos, M.K., 2013. Where does plasma methylglyoxal originate from? Diabetes Research and Clinical Practice 99, 260-271.

Kenagy, R.D., Hart, C.E., Stetler-Stevenson, W.G., Clowes, A.W., 1997. Primate smooth muscle cell migration from aortic explants is mediated by endogenous platelet-derived growth factor and basic fibroblast growth factor acting through matrix metalloproteinases 2 and 9 Circulation 96, 3555-3560. Kleinert, H., Pautz, A., Linker, K., Schwarz, P.M., 2004. Regulation of the expression of inducible nitric oxide synthase. European Journal of Pharmacology 500, 255-266.

Lim, E.L., Hollingsworth, K.G., Smith, F.E., Thelwall, P.E., Taylor, R., 2011. Inhibition of lipolysis in type 2 diabetes normalizes glucose disposal without change in muscle glycogen synthesis rate. Clinical Science 121, 169-177.

Lin, M.I., Fulton, D., Babbitt, R., Fleming, I., Busse, R., Pritchard, K.A., Sessa, W.C., 2003.

Phosphorylation of threonine 497 in endothelial nitric-oxide synthase coordinates the coupling of Larginine metabolism to efficient nitric oxide production. Journal of Biological Chemistry 278, 4471944726.

Lucotti, P., Setola, E., Monti, L.D., Galluccio, E., Costa, S., Sandoli, E.P., Fermo, I., Rabaiotti, G., Gatti, R., Piatti, P.M., 2006. Beneficial effects of a long-term oral l-arginine treatment added to a hypocaloric diet and exercise training program in obese, insulin-resistant type 2 diabetic patients. American Journal of Physiology - Endocrinology and Metabolism 291, E906-E912.

McRae, M.P., 2016. Therapeutic benefits of L-arginine: An umbrella review of meta-analyses. Journal of Chiropractic Medicine 15, 184-189.

Nagareddy, P.R., Xia, Z., McNeill, J.H., MacLeod, K.M., 2005. Increased expression of iNOS is associated with endothelial dysfunction and impaired pressor responsiveness in streptozotocininduced diabetes. American Journal of Physiology-Heart and Circulatory Physiology 289, H2144H2152.

Nicolay, J.P., Schneider, J., Niemoeller, O.M., Artunc, F., Otin, M.P., Haik Jr., G., Thornalley, P.J., Schleicher, E., Wieder, T., Lang, F., 2006. Stimulation of suicidal erythrocyte death by methylglyoxal. Cell Physiol Biochem 18, 223-232.

Nigro, C., Raciti, G.A., Leone, A., Flemin, T.H., Longo, M., Prevenzano, I., Fiory, F., Mirra, P., D’Esposito, V., Ulianich, L., Nawroth, P.P., Formisano, P., Beguinot, F., Miele, C., 2014. Methylglyoxal impairs endothelial insulin sensitivity in both in vitro and in vivo. Diabetologia 57, 1485-1494. 
Accepted version of: Shamsaldeen, Y., Alsugoor, M., Lione, L., \& Benham, C. (2019). Dysfunction in nitric oxide synthesis in streptozotocin treated rat aorta and role of methylglyoxal. European Journal of Pharmacology, 842, 321-328. [EJP-48005R3]. https://doi.org/10.1016/j.ejphar.2018.10.056

Ramasamy, R., Vannucci, S.J., Yan, S.S.D., Herold, K., Yan, S.F., Schmidt, A.M., 2005. Advanced glycation end products and RAGE: a common thread in aging, diabetes, neurodegeneration, and inflammation. Glycobiology 15, 16R-28R.

Schott, C.A., Gray, G.A., Stoclet, J.C., 1993. Dependence of endotoxin-induced vascular hyporeactivity on extracellular I-arginine. British Journal of Pharmacology 108, 38-43.

Schwedhelm, E., Maas, R., Freese, R., Jung, D., Lukacs, Z., Jambrecina, A., Spickler, W., Schulze, F., Böger, R.H., 2008. Pharmacokinetic and pharmacodynamic properties of oral L-citrulline and Larginine: impact on nitric oxide metabolism. BJCP 65, 51-59.

Shamsaldeen, Y.A., Mackenzie, L.S., Lione, L.A., Benham, C.D., 2016. Methylglyoxal, a metabolite increased in diabetes is associated with insulin resistance, vascular dysfunction and neuropathies. Current Drug Metabolism 17, 359-367.

Shamsaldeen, Y.A., Ugur, R., Benham, C.D., Lione, L.A., 2018. Diabetic dyslipidaemia is associated with alterations in eNOS, caveolin-1, and endothelial dysfunction in streptozotocin treated rats. Diabetes/metabolism research and reviews, e2995.

Sheader, E.A., Benson, R.S.P., Best, L., 2001. Cytotoxic action of methylglyoxal on insulin-secreting cells. Biochemical Pharmacology 61, 1381-1386.

Thornalley, P.J., Jahan, I., Ng, R., 2001. Suppression of the accumulation of triosephosphates and increased formation of methylglyoxal in human red blood cells during hyperglycaemia by thiamine in vitro. J. Biochem 129, 543-549.

Uchida, K., 2000. Role of reactive aldehyde in cardiovascular diseases. Free Radical Biology \& Medicine 28, 1685-1696.

Uemura, S., Rothbard, J.B., Matsushita, H., Tsao, P.S., Fathman, C.G., Cooke, J.P., 2002. Short polymers of arginine rapidly translocate into vascular cells effects on nitric oxide synthesis. Circulation Journal 66, 1155-1160.

Van Eupen, M.G.A., Scharm, M.T., Colhoun, H.M., Hansen, N.M.J., Niessen, H.W.M., Tarnow, L., Parving, H.H., Rossing, P., Stehouwer, C.D.A., Schalkwijk, C.G., 2013. The methylglyoxal-derived AGE tetrahydropyrimidineis increased in plasma of individuals with type 1 diabetes mellitus and in atherosclerotic lesions and is associated with sVCAM-1. Diabetologia 56, 1845-1855.

Vanhoutte, P.M., Zhao, Y., Xu, A., Leung, S.W., 2016. Thirty Years of Saying NO. Circulation Research $119,375-396$.

Wong, C.M., Au, C.L., Tsang, S.Y., Lau, C.W., Yao, X., Cai, Z., Chung, A.C.K., 2017. Role of inducible nitric oxide synthase in endothelium-independent relaxation to raloxifene in rat aorta. British Journal of Pharmacology 174, 718-733.

Wu, C.-C., Szabo, C., Chen, S.-J., Thiemermann, C., Vane, J.R., 1994. Activation of soluble guanylyl cyclase by a factor other than nitric oxide or carbon monoxide contributes to the vascular hyporeactivity to vasoconstrictor agents in the aorta of rats treated with endotoxin. Biochemical and Biophysical Research Communications 201, 436-442.

Yamawaki, H., Saito, K., Okada, M., Hara, Y., 2008. Methylglyoxal mediates vascular inflammation via JNK and p38 in human endothelial cells. American Journal of Physiology - Cell Physiology 295, c1510c1517. 


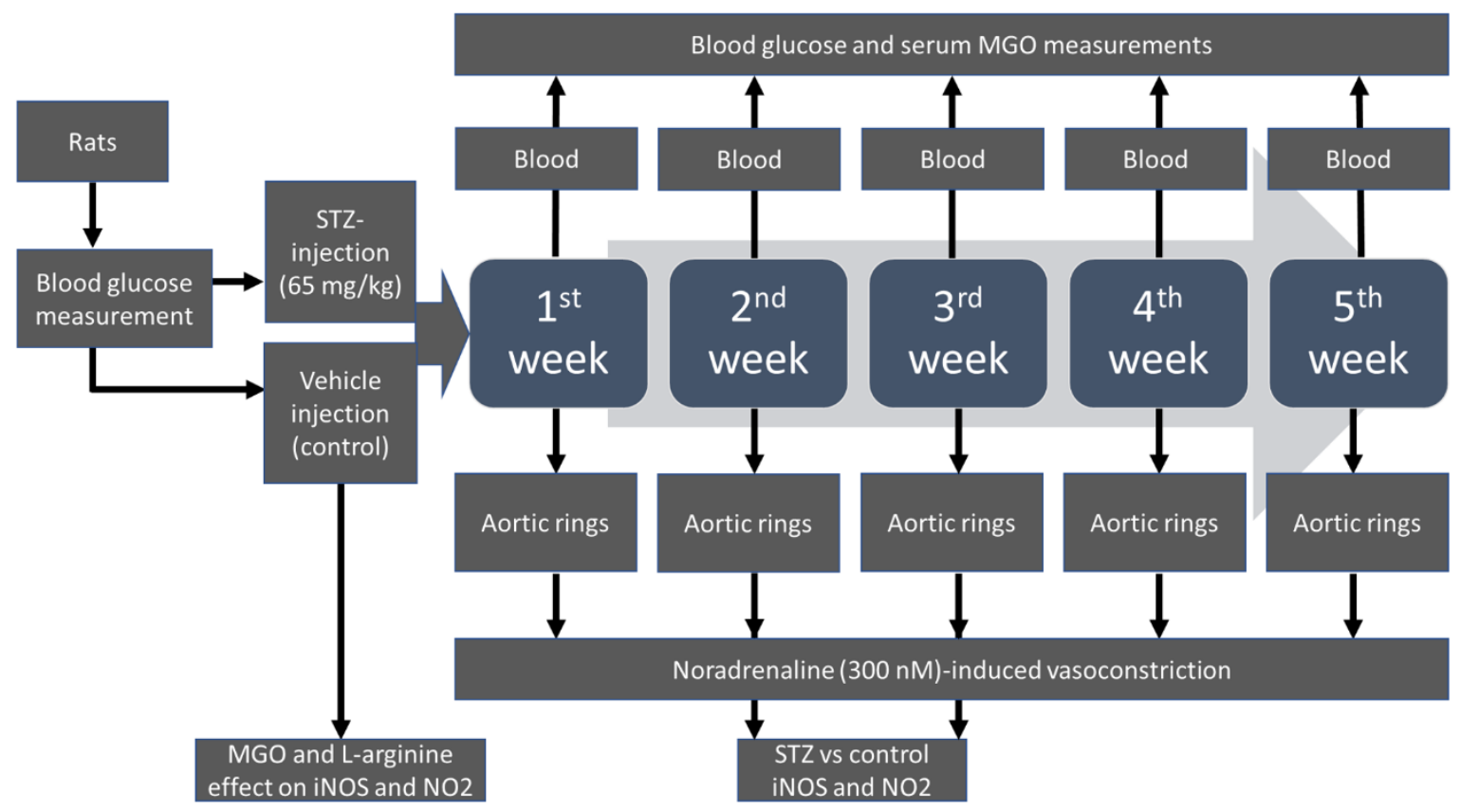

Fig. 1 Schematic diagram describing the methodology of the STZ-diabetic rat studies. iNOS: inducible nitric oxide synthase, MGO: methylglyoxal, $\mathrm{NO}_{2}$ t total nitrite and STZ: streptozotocin. 


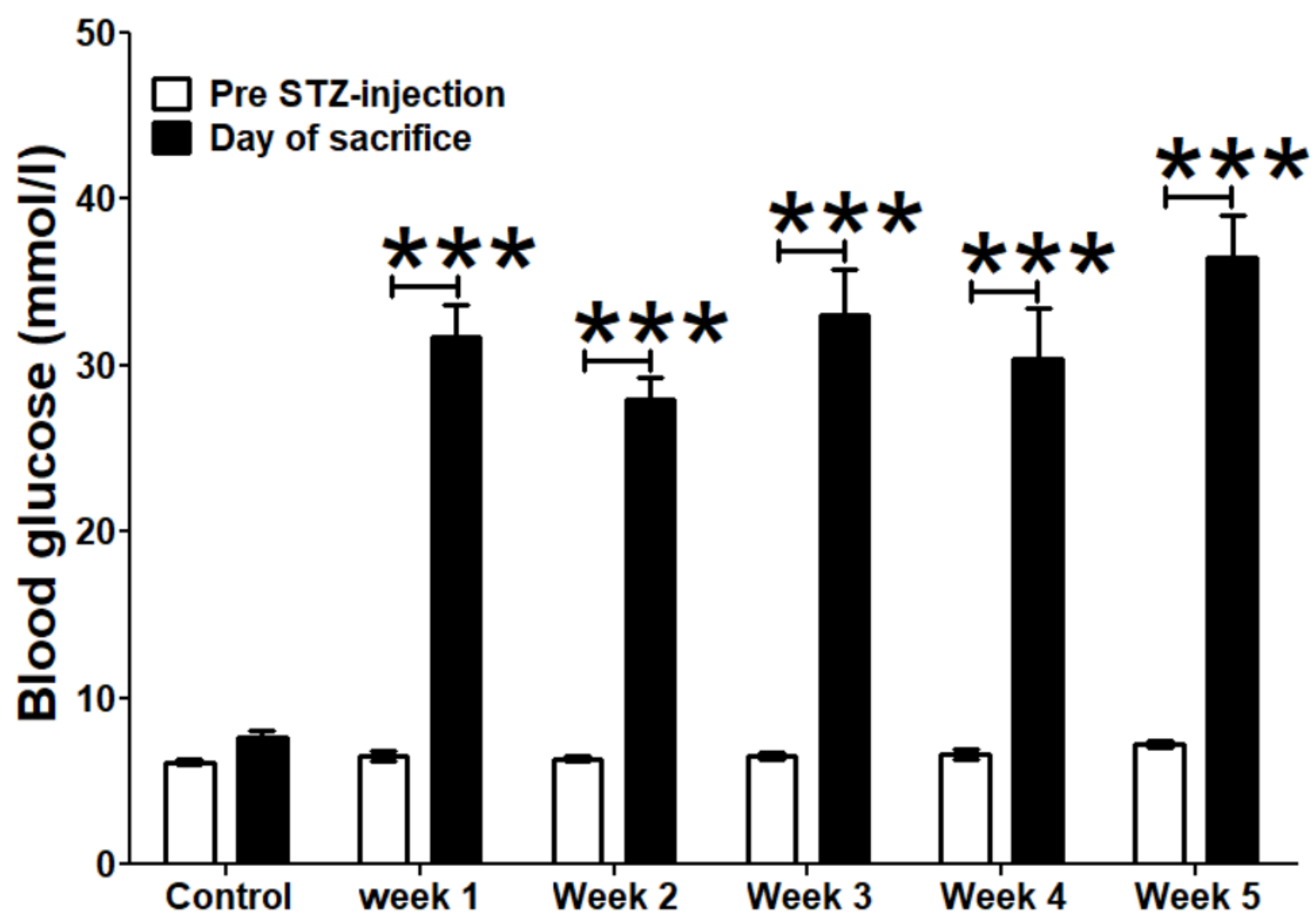

Fig. 2 Blood glucose is elevated in streptozotocin (STZ) treated rats. Blood glucose concentration was measured pre- injection and on the day of sacrifice from week 1-5 post STZ-injection using an Accu-check Aviva (Roche) blood glucose meter. At weeks 1-5 the day of sacrifice values are compared with the pre-injection values for the same rats. Data shown as mean \pm S.E.M. $(\mathrm{N}=5)$ and significance is represented as ${ }^{* * *}=\mathrm{P}<0.001$ versus preinjection analyzed by paired two-tailed Student t-test. 


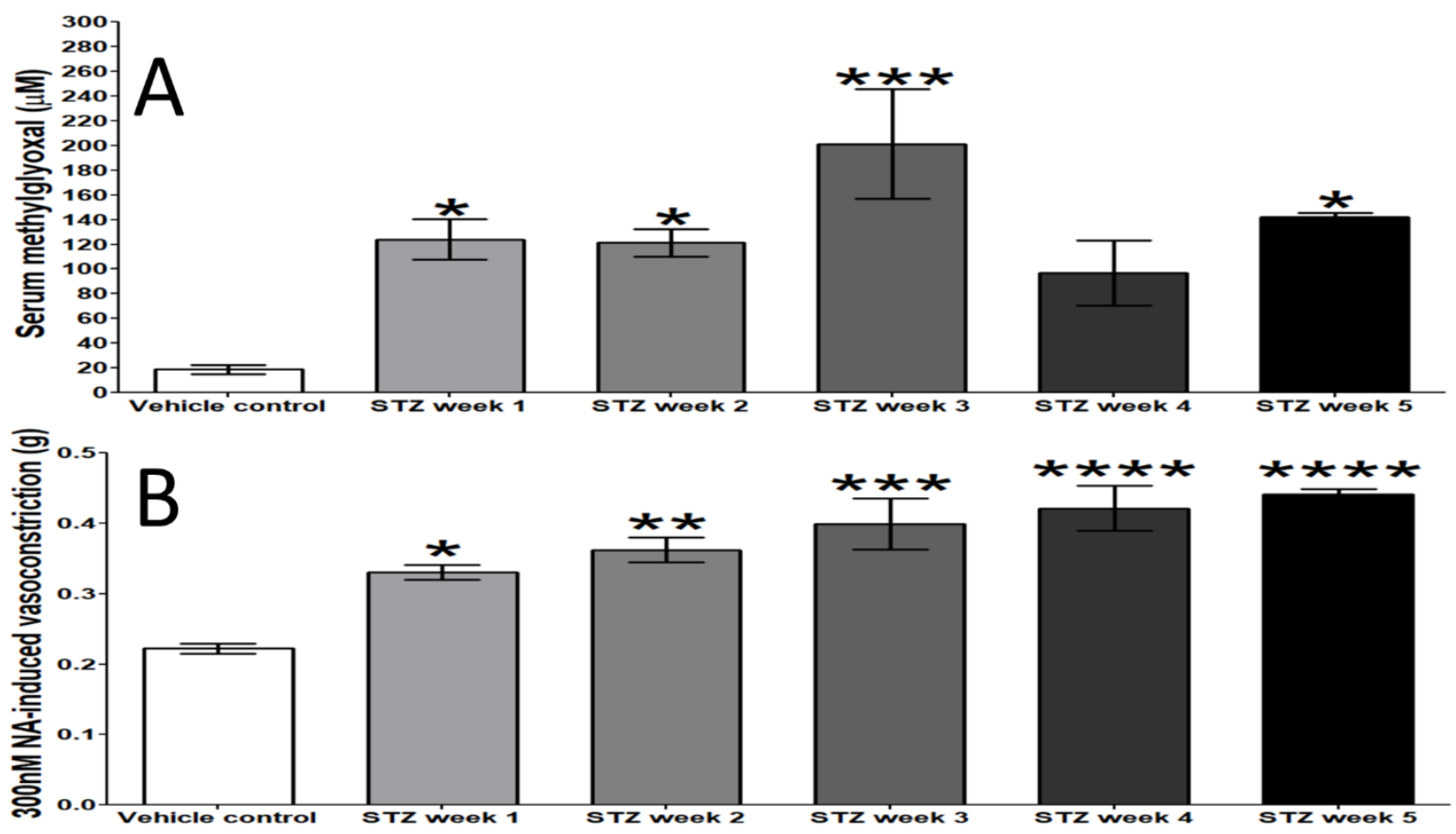

Fig. 3 Serum methylglyoxal in streptozotocin (STZ)-injected rats is increased relative to vehicle control (A) and aortic ring contractility to noradrenaline (NA) (B). Data are presented as mean \pm S.E.M. (A) serum methylglyoxal from vehicle control and STZ-diabetic rats from week 1 to week 5 (vehicle control, $\mathrm{N}=4$; week 1 , $\mathrm{N}=4$; week 2, $\mathrm{N}=5$; week $3, \mathrm{~N}=4$; week $4, \mathrm{~N}=4$; week $5, \mathrm{~N}=4$. (B) Contractility of aortic rings from vehicle control and STZ-treated rats at weekly intervals post injection (vehicle control $\mathrm{N}=4$; week $1, \mathrm{~N}=4$; week 2, N=5 ; week 3, N= 5; week 4, N=5; week 5, N=4;) significance is represented as ${ }^{*}=\mathrm{P}<0.05,{ }^{* *}=\mathrm{P}<0.01,{ }^{* * *}=\mathrm{P}<0.001$ and $* * * *=\mathrm{P}<0.0001$ versus control, one-way ANOVA with Tukey post-hoc test. 


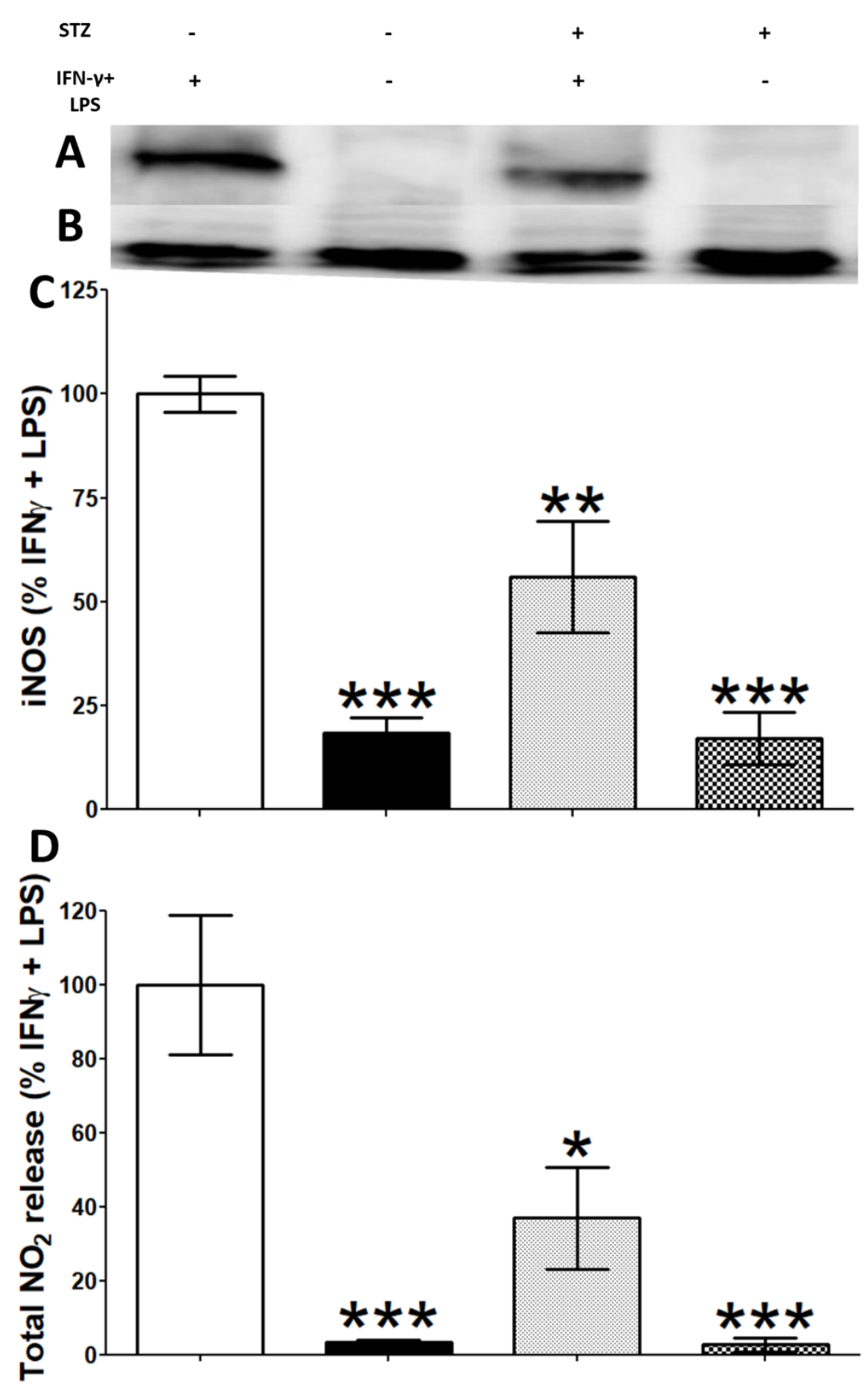

Fig. 4 Inducible nitric oxide synthase (iNOS) expression and total nitrite $\left(\mathrm{NO}_{2}\right)$ production is reduced in rat aortic smooth muscle cells (ASMCs) from streptozotocin (STZ) treated rats. Western blots of iNOS expression in STZ-treated and vehicle control ASMCs treated with IFN- $\gamma$ and LPS (A). $\beta$-actin bands (B). Densitometric analysis of iNOS expression in STZ-treated and vehicle control ASMCs $(\mathrm{N}=5)(\mathrm{C})$. Griess assay of total $\mathrm{NO}_{2}$ released from STZ-treated and vehicle control ASMCs $(\mathrm{N}=6)(\mathrm{D})$. Data are presented as mean \pm S.E.M. iNOS expression after normalising to beta actin was normalized as percentage of the positive vehicle control iNOS expression. Total $\mathrm{NO}_{2}$ was normalized as percentage of the positive vehicle control total $\mathrm{NO}_{2}$ release. Significance is represented as ${ }^{*}=\mathrm{P}<0.05,^{* *}=\mathrm{P}<0.01$ and ${ }^{* * *}=\mathrm{P}<0.001$ by one-way ANOVA with Tukey post-hoc test. 

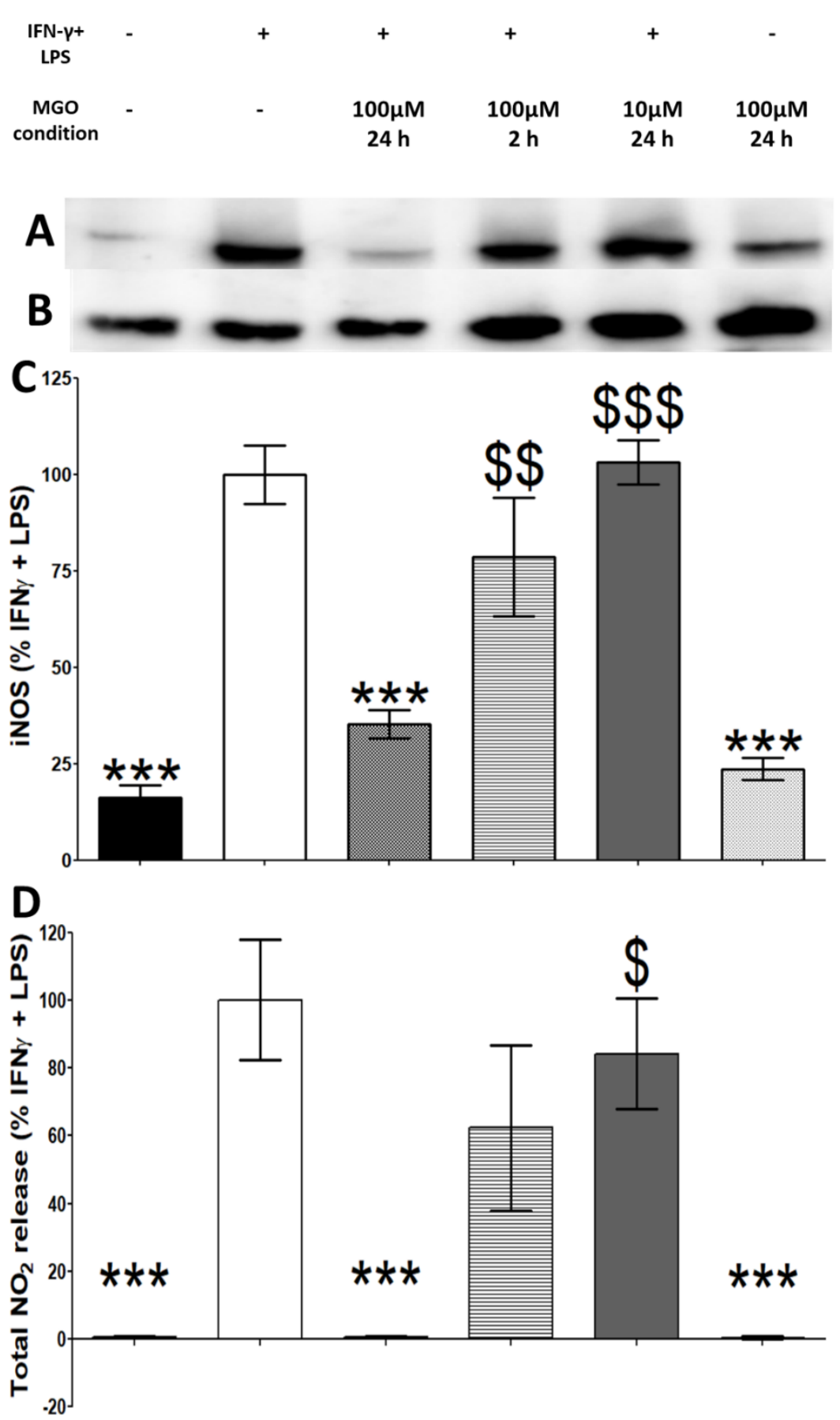

Fig. 5 Inhibition of inducible nitric oxide synthase (iNOS) expression and total nitrite $\left(\mathrm{NO}_{2}\right)$ release in ASMCs by methylglyoxal (MGO). Western blots of iNOS expression (A). $\beta$-actin bands (B). Densitometric analysis of inducible nitric oxide synthase (iNOS) expression with/without interferon- $\gamma$ (IFN- $\gamma$ ), lipopolysaccharide (LPS) treated with MGO (0, 10, $100 \mu \mathrm{M})$ and with MGO $(100 \mu \mathrm{M})$ only (C). Griess assay of total $\mathrm{NO}_{2}$ released from ASMCs incubated with/without interferon- $\gamma($ IFN- $\gamma$ ), lipopolysaccharide (LPS) treated with MGO $(0,10,100 \mu \mathrm{M})$ and with MGO $(100 \mu \mathrm{M})$ only (D). Data are presented as mean \pm S.E.M.; $(\mathrm{N}=4)$. iNOS expression after normalising to beta actin was normalized as a percentage of the positive control iNOS expression. Total $\mathrm{NO}_{2}$ was normalized as percentage of the positive control total $\mathrm{NO}_{2}$ release. Significance is represented as ${ }^{* * *}=\mathrm{P}<0.001$ versus positive control, $\$=\mathrm{P}<0.05, \$ \$=\mathrm{P}<0.01$ and $\$ \$ \$=\mathrm{P}<0.001$ versus IFN $-\gamma+\mathrm{LPS}+$ MGO $(100 \mu \mathrm{M})$ for $24 \mathrm{~h}$ analyzed by Tukey's one-way ANOVA. 


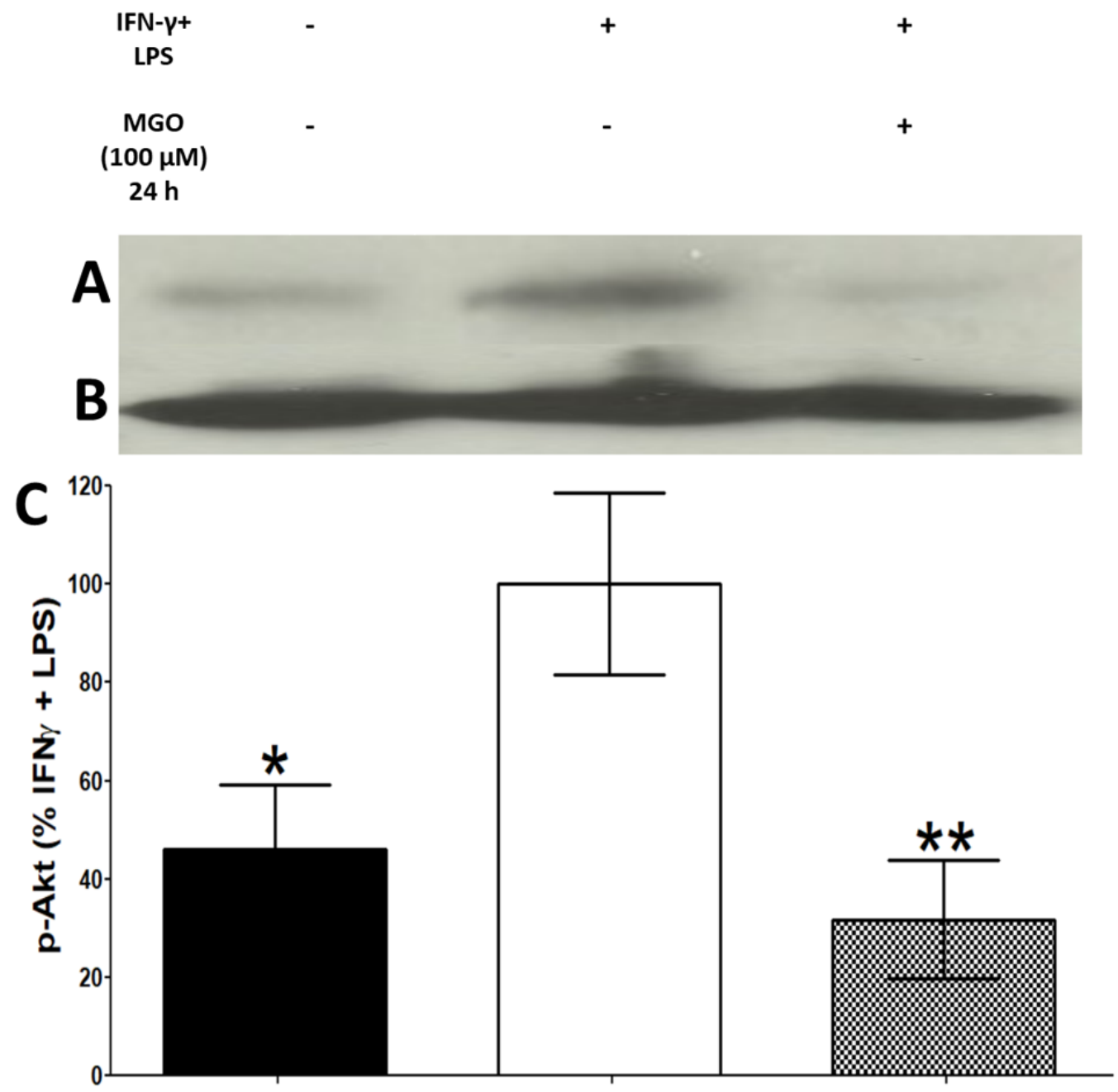

Fig. 6 IFN- $\gamma$ and LPS stimulation of Akt phosphorylation is blocked by methylglyoxal (MGO) $100 \mu \mathrm{M}$. SDSPAGE western blotting showing p-Akt expression bands (A). $\beta$-actin bands (B). ASMCs were incubated with IFN- $\gamma$, LPS and MGO $100 \mu \mathrm{M}$ for $24 \mathrm{~h}$ compared to positive control ASMCs were incubated with IFN- $\gamma$ and LPS only (C). Data are presented as mean \pm S.E.M.; $(\mathrm{N}=3)$. Phosphorylated Akt ( $\mathrm{p}-\mathrm{Akt}$ ) after normalising to beta actin was normalized as percentage of the positive control $\mathrm{p}$-Akt expression Significance is represented as ${ }^{*}=\mathrm{P}<0.05$ and ${ }^{* *}=\mathrm{P}<0.01$ by Tukey's one-way ANOVA. 


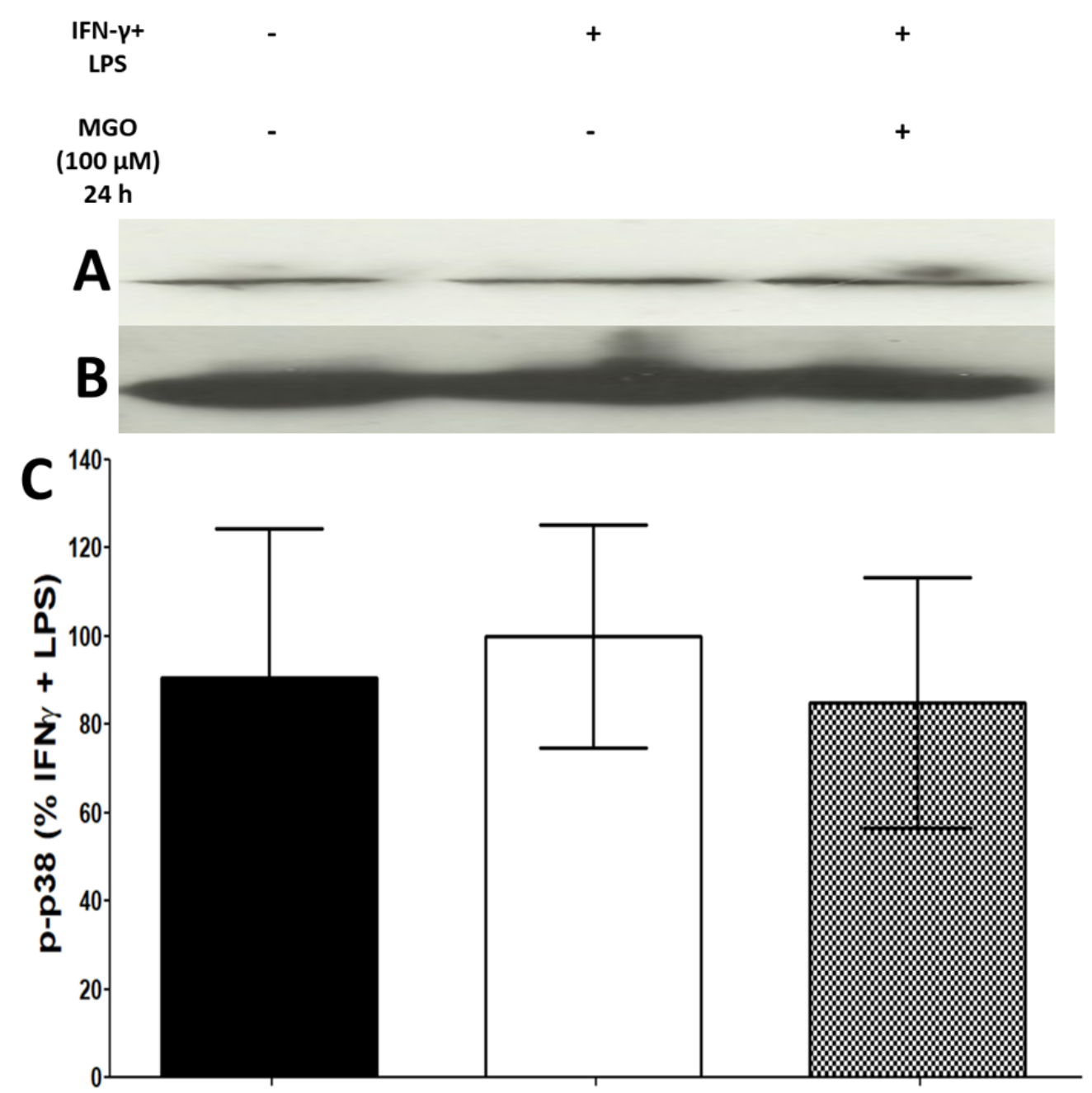

Fig. 7 IFN- $\gamma$ and LPS do not stimulate p38 phosphorylation. SDS-PAGE western blotting showing p-p38 expression bands (A). $\beta$-actin bands (B). Densitometric analysis of p-p38 expression in ASMCs were incubated with IFN- $\gamma$, LPS and MGO $100 \mu \mathrm{M}$ for $24 \mathrm{~h}$ compared to ASMCs incubated with IFN- $\gamma$ and LPS only $(\mathrm{N}=3)(\mathrm{C})$. Data are presented as mean \pm S.E.M.; $(\mathrm{N}=3)$. Phosphorylated p38 (p-p38) after normalizing to beta actin was normalized as percentage of the positive control p-p38 expression, showing non-significant effect $\mathrm{P}>0.05$ by Tukey's one-way ANOVA. 

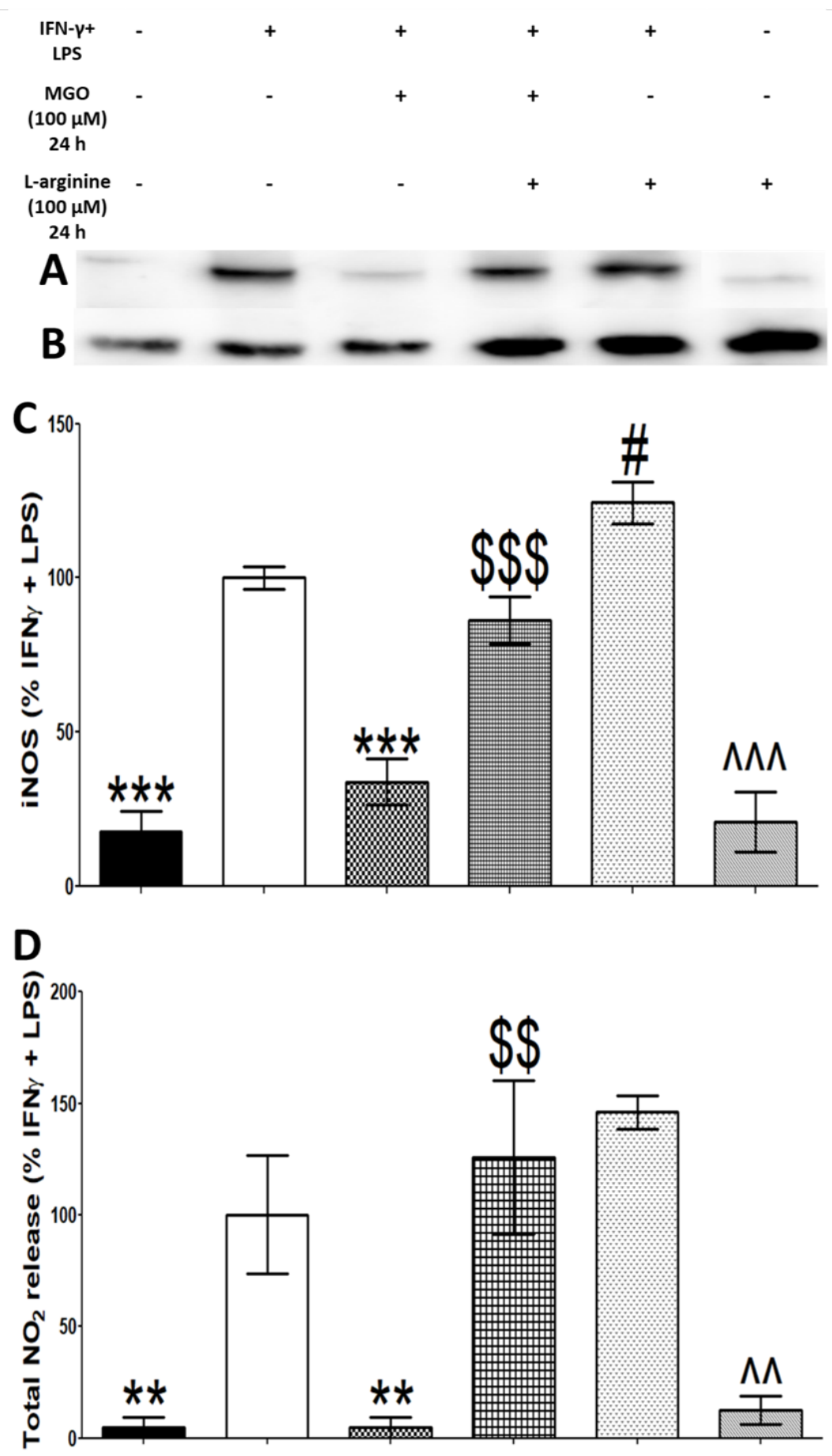

Fig. 8. MGO inhibition of IFN- $\gamma$ and LPS stimulated inducible nitric oxide synthase (iNOS) expression and total nitrite $\left(\mathrm{NO}_{2}\right)$ release is prevented by L-arginine co-incubation. SDS-PAGE Western blot for iNOS expression (A). $\beta$-actin bands (B). Densitometric analysis of ASMCs inducible nitric oxide synthase (iNOS) expression with/without interferon- $\gamma($ IFN- $\gamma$ ) and lipopolysaccharide (LPS) with/without methylglyoxal (MGO) $(100 \mu \mathrm{M})$ and L-arginine $(100 \mu \mathrm{M})(\mathrm{C})$. Griess assay of total $\mathrm{NO}_{2}$ released from ASMCs with/without methylglyoxal (MGO) and L-arginine (D). Data are presented as mean \pm S.E.M.; $(\mathrm{N}=4)$. iNOS expression after normalising to beta actin was normalized as percentage of the positive control iNOS expression. Total $\mathrm{NO}_{2} \mathrm{was}$ normalized as percentage of the positive control total $\mathrm{NO}_{2}$ - release. Significance is represented as ${ }^{* *}=\mathrm{P}<0.01$ and *** $=\mathrm{P}<0.001$ versus positive control, $\$ \$=\mathrm{P}<0.01$ and $\$ \$ \$=\mathrm{P}<0.001$ versus IFN- $\gamma+$ LPS + MGO $24 \mathrm{~h}, \#=\mathrm{P}<0.05$

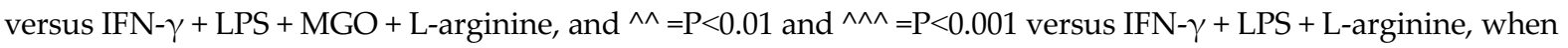
analysed by Tukey's one-way ANOVA. 
Accepted version of: Shamsaldeen, Y., Alsugoor, M., Lione, L., \& Benham, C. (2019). Dysfunction in nitric oxide synthesis in streptozotocin treated rat aorta and role of methylglyoxal. European Journal of Pharmacology, 842, 321-328. [EJP-48005R3]. https://doi.org/10.1016/j.ejphar.2018.10.056 
Accepted version of: Shamsaldeen, Y., Alsugoor, M., Lione, L., \& Benham, C. (2019). Dysfunction in nitric oxide synthesis in streptozotocin treated rat aorta and role of methylglyoxal. European Journal of Pharmacology, 842, 321-328. [EJP-48005R3]. https://doi.org/10.1016/j.ejphar.2018.10.056 